\title{
Studies on Structure of Cuprammonium Cellulose I. A Circular Dichroism Study on the Dissolved State of Cellulose in Cuprammonium Solution
}

\author{
Ikuya MiYamoto, Miki Inamoto, Toshihiko Matsui, \\ Masatoshi SAITo, and Kunihiko OKaJIMA \\ Fundamental Research Laboratory of Natural \& Synthetic Polymers, \\ Asahi Chemical Industry Co., Ltd., 11-7 Hacchownawate, \\ Takatsuki, Osaka 569, Japan
}

(Received June 16, 1995)

\begin{abstract}
An attempt was made to clarify the dissolved state of cellulose in aq cuprammonium hydroxide solution using ultraviolet (UV) and circular dichroism (CD) spectrophotometry on cellulose and its oligomers in the solution. Negative Cotton effect and positive Cotton effect for the cellulose-cuprammonium solution are observed at $300-350 \mathrm{~nm}$ and $c a$. $600 \mathrm{~nm}$. The former Cotton effect seems to originate from charge transfer (CT) excitation and the latter from $d-d$ excitation of cupric ion due to coordination of cuprammonium complex to hydroxyl group of cellulose. The experimental fact that intensity of $C D$ for almost $C_{2}-C_{3}$ substituted methyl cellulose in cuprammonium hydroxide is nearly zero leads us to an conclusion that cuprammonium complex coordinates preferentially to hydroxyl groups at $\mathrm{C}_{2}$ and $\mathrm{C}_{3}$, giving $\delta$ chelate form. As a dissolved state of cellulose in aq cuprammonium hydroxide, an equilibrium state between cellulosecuprammonium complex, cellulose and cuprammonium hydroxide was predicted where coppercellulose molar ratio of $c a .0 .6-0.8$ is stable for the cellulose-cuprammonium complex.

KEY WORDS Cuprammonium Cellulose / Circular Dichroism / Cotton Effect / Charge Transfer Excitation / Chelate Conformation / Methyl Cellulose / Equilibrium State /
\end{abstract}

Discovery of a cuprammonium solution as a cellulose solvent by Schweitzer ${ }^{1}$ as early as in 1857 brought about the embryo stage of regenerated cellulose fiber industries. ${ }^{2}$ The technology using this solvent remains still now active for fiber and hollow fiber productions ${ }^{3,4}$ though within very limited countries in the world.

Many cellulose chemists undoubtedly had believed for long years that cellulose dissolves forming certain cellulose-cuprammonium complex in cuprammonium solution and made significant efforts in 1920 to 1950 to speculate the structure of cellulose-cuprammonium complex, ${ }^{5-8}$ but most of them were based on an elementary analysis of the products recovered from cellulose-cuprammonium solution. For example, Traube ${ }^{5}$ proposed the reaction mechanism between cellulose and cuprammonium hydroxide as follows:

$$
\begin{aligned}
& 2\left(\mathrm{C}_{6} \mathrm{H}_{10} \mathrm{O}_{5}\right)+\left[\mathrm{Cu}\left(\mathrm{NH}_{3}\right)_{4}\right](\mathrm{OH})_{2} \rightarrow\left(\mathrm{C}_{6} \mathrm{H}_{9} \mathrm{O}_{5}\right)_{2}^{-}\left[\mathrm{Cu}\left(\mathrm{NH}_{3}\right)_{4}\right]^{2+}+2 \mathrm{H}_{2} \mathrm{O} \\
&\left(\mathrm{C}_{6} \mathrm{H}_{9} \mathrm{O}_{5}\right)_{2}^{-}\left[\mathrm{Cu}\left(\mathrm{NH}_{3}\right)_{4}\right]^{2+}+ {\left[\mathrm{Cu}\left(\mathrm{NH}_{3}\right)_{4}\right](\mathrm{OH})_{2} } \\
& \rightarrow\left[\left(\mathrm{C}_{6} \mathrm{H}_{8} \mathrm{O}_{5}\right)_{2} \mathrm{Cu}\right]^{2-}\left[\mathrm{Cu}\left(\mathrm{NH}_{3}\right)_{4}\right]^{2+}+4 \mathrm{NH}_{3}+2 \mathrm{H}_{2} \mathrm{O} \\
& \hline 2\left(\mathrm{C}_{6} \mathrm{H}_{10} \mathrm{O}_{5}\right)+2\left[\mathrm{Cu}\left(\mathrm{NH}_{3}\right)_{4}\right](\mathrm{OH})_{2} \rightarrow\left[\left(\mathrm{C}_{6} \mathrm{H}_{8} \mathrm{O}_{5}\right)_{2} \mathrm{Cu}\right]^{2-}\left[\mathrm{Cu}\left(\mathrm{NH}_{3}\right)_{4}\right]^{2+}+4 \mathrm{NH}_{3}+4 \mathrm{H}_{2} \mathrm{O}
\end{aligned}
$$


Lieser $^{6}$ proposed another chemical structure of cuprammonium cellulose solid as follows:

$$
\left(\mathrm{C}_{6} \mathrm{H}_{10} \mathrm{O}_{5}\right)\left(\mathrm{C}_{6} \mathrm{H}_{7} \mathrm{O}_{2}\right)\left[\begin{array}{l}
\mathrm{OH} \\
\mathrm{OH} \\
\mathrm{OH}-\left[\mathrm{Cu}(\mathrm{OH})_{2}\right. \\
\left.\mathrm{OH}\left(\mathrm{NH}_{3}\right)_{4}\right](\mathrm{OH})_{2} / 2
\end{array}\right] \text {. }
$$

On the one hand, Neale reported that one mole of copper bonds to one mole of glucose residue for his cuprammonium cellulose. ${ }^{7}$ Thus, these analyses unavoidably proved that structure of cuprammonium cellulose might be greatly influenced by removal or separation method. Furthermore, chemical structure of solid cuprammonium cellulose might not always be the same as that in solution.

In order to avoid these effects of treatment,
Hess and his coworkers ${ }^{8}$ studied the optical rotation and electrophoresis of cellulose-cuprammonium solution system and found that optical rotation is determined by the concentration of cuprammonium cellulose in solution and complex formed between copper and decomposed cellulose was precipitated on cathode by electrophoresis, proposing the following reaction scheme:

$$
\begin{aligned}
& 2\left(\mathrm{C}_{6} \mathrm{H}_{10} \mathrm{O}_{5}\right)+\left[\mathrm{Cu}\left(\mathrm{NH}_{3}\right)_{4}\right]^{2+}(\mathrm{OH})_{2}^{-} \rightarrow\left(\mathrm{C}_{6} \mathrm{H}_{9} \mathrm{O}_{5}\right)_{2}-\left[\mathrm{Cu}\left(\mathrm{NH}_{3}\right)_{4}\right]^{2+}+2 \mathrm{H}_{2} \mathrm{O} \\
&\left(\mathrm{C}_{6} \mathrm{H}_{9} \mathrm{O}_{5}\right)_{2}-\left[\mathrm{Cu}\left(\mathrm{NH}_{3}\right)_{4}\right]^{2+}+ 2\left[\mathrm{Cu}\left(\mathrm{NH}_{3}\right)_{4}\right]^{2+}(\mathrm{OH})_{2}^{-} \\
&\left.\rightarrow\left[\mathrm{C}_{6} \mathrm{H}_{7} \mathrm{O}_{5}\right)_{2} \mathrm{Cu}\right]_{2}^{-}\left[\mathrm{Cu}\left(\mathrm{NH}_{3}\right)_{4}\right]^{2+}+8 \mathrm{NH}_{3}+4 \mathrm{H}_{2} \mathrm{O} \\
& \hline 2\left(\mathrm{C}_{6} \mathrm{H}_{10} \mathrm{O}_{5}\right)+3\left[\mathrm{Cu}\left(\mathrm{NH}_{3}\right)_{4}\right](\mathrm{OH})_{2} \rightarrow\left[\left(\mathrm{C}_{6} \mathrm{H}_{7} \mathrm{O}_{5}\right) \mathrm{Cu}\right]_{2}\left[\mathrm{Cu}\left(\mathrm{NH}_{3}\right)_{4}\right]+8 \mathrm{NH}_{3}+4 \mathrm{H}_{2} \mathrm{O}
\end{aligned}
$$

Later in 1944, Reeves ${ }^{9}$ also carried out the optical rotation study finding that cuprammonium cellulose solution exhibited a levorotation at $436 \mathrm{~nm}$ and he stressed that the levorotation was caused by the existence of cuprammonium cellulose complex. He also synthesized $\beta$-methyl glucose derivatives of which the hydroxyl groups at $\mathrm{C}_{2}, \mathrm{C}_{3}, \mathrm{C}_{4}$, or $\mathrm{C}_{6}$ positions were selectively masked and found that the solution has almost the same value in molecular rotatory power as the solution of cellulose only when both hydroxy group at $\mathrm{C}_{2}$ and $\mathrm{C}_{3}$ positions of the glucose was not substituted, leading to a conclusion that the optical rotatory power of the solution was originated by a complex in which copper coordinates to $\mathrm{C}_{2}, \mathrm{C}_{3}$ hydroxyl groups of glucose residue. He proposed that the structure of cellulose-cuprammonium complex is a $1: 1 \mathrm{~mol}$ salt of cuprammonium complex cation and diol anion at $\mathrm{C}_{2}$ and $\mathrm{C}_{3}$ positions on pyranose ring of cellulose. This structure is believed as a cellulose-cupram- monium complex structure in the cuprammonium solution. His studies are elegant and more reliable because of free of separation procedure of the complex. However, these results are not quantitative in strict sense and much more will be needed for explaining the origin of optical rotation in relation to more detailed nature of the complex. Other voluminous studies on cuprammonium cellulose solid or its solution had been made, but even the molar ratio of copper and glucopyranose unit was not settled down.

In 1960s, the development of optical rotatory dispersion (ORD) and circular dichroism (CD) measurements encouraged to study the conformation or configuration of complexes in solvents. Bukhari et al. ${ }^{10,11}$ studied the CD spectra of cyclic 1,2 diols and 1,2 amino alcohols in aqueous cuprammonium hydroxide solution having variety of configuration, revealing that 1) two CD peaks near 600 and $300 \mathrm{~nm}$ are detected for the case where two 
hydroxyl groups are placed in gauche conformation, 2) no peak is detectable when two hydroxyl groups are in trans conformation, 3) Cotton effect is reversed when the gauche angle goes from positive to negative. They pointed out that copper ion forms chelate coordination with two hydroxyl groups and conformation of the chelate might determine the nature of Cotton effect. These results might be applicable to cellulose-cuprammonium solution system. Bukhari et al. have succeeded to clarify that the origin of asymmetry is chelate conformation but reserved to clear the origin of $a b-$ sorption band for generating Cotton effect.

In this study, an attempt was made to elucidate the coordination cite on cellulose of copper, coordination molar ratio of copper to cellulose, and conformation of the complex for cellulose-cuprammonium solution system from their ultra-violet (UV)-visible light absorption spectra and CD spectra.

\section{EXPERIMENTAL}

\section{Materials}

Cellulose. Alaska pulp with viscosity-average molecular weight $M_{v}=1.72 \times 10^{5}$ and $\alpha$ cellulose content $=90.1 \mathrm{wt} \%$ was treated by steam-explosion method under the conditions described in the previous study. ${ }^{12} M_{v}$ of the treated cellulose sample was estimated as $5.36 \times 10^{4}$ through the equation $[\eta]=3.85 \times$ $10^{-2} M_{w}^{0.76}\left(\mathrm{~cm}^{3} \mathrm{~g}^{-1}\right)$ established for cellulosecadoxen system, ${ }^{13}$ where $[\eta]$ and $M_{w}$ are the limiting viscosity number in cadoxen (cadmium oxide-ethylendiamine- $\mathrm{NaOH}-\mathrm{H}_{2} \mathrm{O}=5: 29$ : $1.4: 166, \mathrm{w} / \mathrm{w} / \mathrm{w} / \mathrm{w})$ and the weight-average molecular weight, respectively. And its degree of break-down of intramolecular hydrogen bond $\left(\chi_{\mathrm{am}}\left(\mathrm{C}_{3}+\mathrm{C}_{6}\right)\right)$ determined by CP/MASS ${ }^{13} \mathrm{C}$ NMR method ${ }^{14}$ was $48 \%$.

Cellulose Oligomer. Cellobiose, cellotriose, cellotetraose, and cellopentaose/supplied from Aldrich Co., Ltd. (U.S.A.) were used as received.

Methyl Cellulose (MC). Non-regioselective- ly-substituted MC (RMC with total degree of substitution $\langle\langle F\rangle\rangle=1.98$ ) was supplied from Kishida Chemicals Co., Ltd. (Tokyo). Regioselectively-substituted $\mathrm{MC}$ at $\mathrm{C}_{2}$ and $\mathrm{C}_{3}$ position with $\langle\langle F\rangle\rangle=1.68$ (SMC) was synthesized by the procedure proposed by Kondo et al. ${ }^{15}$ using the cellulose described above. Probability of substitution at $\mathrm{C}_{2}, \mathrm{C}_{3}$, and $\mathrm{C}_{6}(\langle f k\rangle\rangle, k=$ $2,3,6)$ was determined from methyl carbon peak intensities of MC dissolved in dimethyl sulfoxide (DMSO) in ${ }^{13} \mathrm{C}$ NMR spectrum. ${ }^{16}$ The ${ }^{13} \mathrm{C}$ NMR measurements using a FTNMR spectrometer (GSX 400, JEOL) were made under the following conditions: Frequency on carbon atom, $100.2 \mathrm{MHz}$; data point, 32768; accumulation, 20000; flip angle, $45^{\circ}$; pulse mode, gated proton-decouple without NOE; pulse interval, $5 \mathrm{~s}$; solvent, DMSO$d_{6}$; internal standard, tetramethyl silane.

Preparation of Solutions. A $25 \mathrm{wt} \%$ of aq ammonia $\left(\mathrm{NH}_{3}\right)$ solution (supplied from Kishida Chemicals Co., Ltd.) was diluted by deionized water giving aq ammonia solution with desired concentrations. Into the solution, an excess amount of cupric hydroxide was added saturatedly at room temperature and the solution obtained was stood for $10 \mathrm{~h}$ at $5^{\circ} \mathrm{C}$. Then we filtered off the excess cupric hydroxide in the solution and obtained the cuprammonium solution with the composition of $\mathrm{Cu}$ / $\mathrm{NH}_{3}=0.089 / 7.94$ and $0.055 / 7.94(\mathrm{~mol} / \mathrm{mol})$ for the case using $12.5 \mathrm{wt} \%$ aq ammonium solution. The compositions of the above aq cuprammonium solution is expressed in weight basis as $\mathrm{Cu} / \mathrm{NH}_{3} / \mathrm{H}_{2} \mathrm{O}=0.8 / 12.5 / 86.7$ and $0.5 /$ $12.5 / 86.4$ for the sake of simplicity. Note that in practical cellulose dissolving process an addition of small amount of $\mathrm{NaOH}$ in the aq cuprammonium hydroxide solution is said to facilitate the dissolution of cellulose, but in the present study this effect is neglected.

Polymer-aq Cuprammonium Hydroxide Solution Systems. Cellulose and MC were added into $10 \mathrm{~g}$ of the aq cuprammonium hydroxide solution with the afore-mentioned compositions at $5^{\circ} \mathrm{C}$ stood for $24 \mathrm{~h}$ with intermittent 
agitation, so as to give the desired concentrations. When we prepare the cellulose solution with different copper concentrations, the cellulose solution with $\mathrm{Cu} / \mathrm{NH}_{3} / \mathrm{H}_{2} \mathrm{O}=0.5 / 12.5 /$ 86.4 was diluted by $12.5 \%$ aq $\mathrm{NH}_{3}$ solution. $0.025 \mathrm{~g}$ of cellulose oligomer was dissolved into $10 \mathrm{~g}$ of the aq cuprammonium solution with $\mathrm{Cu} / \mathrm{NH}_{3} / \mathrm{H}_{2} \mathrm{O}=0.5 / 12.5 / 86.4$ following to the same procedure as the case of cellulose and MC. Copper concentration in the aq cellotetraose and cellopentaose soln was changed by putting the $\mathrm{Cu}(\mathrm{OH})_{2}$ powder into $2 \mathrm{~g}$ of each oligomer solution with oligomer concentration of $1 \mathrm{wt} \%$. The resultant solutions were subjected to UV and CD measurements. As a reference solution, the cellulose-aq sodium hydroxide solution system reported in the previous study ${ }^{14}$ was used.

$C D$ Measurement. CD spectra of the solutions were recorded on a spectrophotometer model J-720 (JASCO, Japan) at $25^{\circ} \mathrm{C}$ in a quart cell with light pass length $=1 \mathrm{~mm}$ or $0.1 \mathrm{~mm}$ under the following conditions: Band width, $1.0 \mathrm{~nm}$; sensitivity, $1000 \mathrm{mdeg}$; response, $0.5 \mathrm{~s}$; scan speed, $500 \mathrm{~nm} \mathrm{~min}^{-1}$; wavelength range, $800-200 \mathrm{~nm}$.

UV Measurement. UV spectra of the solutions were recorded on a UV spectrophotometer (UV-3400 spectrophotometer, Hitachi Co., Ltd., Japan) in a quart cell with light pass length $=1 \mathrm{~mm}$ at $25^{\circ} \mathrm{C}$ in wavelength $\left(\lambda_{\mathrm{UV}}\right)$ range of $800-200 \mathrm{~nm}$.

$\mathrm{Cu}$ Contents in the Cellulose-aq Cuprammonium Systems during Coagulation. Cellulose-cuprammonium solution $\left(\mathrm{Cell} / \mathrm{Cu} / \mathrm{NH}_{3} /\right.$ $\mathrm{H}_{2} \mathrm{O}=0.68 / 0.62 / 4.16 / 47.86 \mathrm{moll}^{-1}$ ) was cast on a glass plate so as to give thickness of the solution of $0.27 \mathrm{~mm}$ and the plate was immersed into the deionized water at temperatures of 9 and $40^{\circ} \mathrm{C}$. Copper contents of the films obtained after desired time lapse were estimated by Iodo-titration method.

\section{RESULTS AND DISCUSSION}

Figure 1 shows UV spectra of aq $15 \mathrm{wt} \%$
$\mathrm{NH}_{3}$ solution (a), aq cuprammonium hydroxide solution $\left(\mathrm{Cu} / \mathrm{NH}_{3} / \mathrm{H}_{2} \mathrm{O}=0.8 / 12.5 / 86.7\right)(b)$, $0.8 \mathrm{wt} \%$ cellulose solution dissolved in the above solution (c), $0.8 \mathrm{wt} \%$ cellulose solution dissolved in $8.7 \mathrm{wt} \%$ aq $\mathrm{NaOH}$ solution (d). The aq cuprammonium hydroxide solution apparently shows UV absorption near $\lambda_{\mathrm{UV}}=$ $260,300,330$, and $630 \mathrm{~nm}$ where no absorption was detected for the aq ammonium solution. A dissolution of cellulose into the aq cuprammonium solution brings about remarkable increase in the absorbance near $\lambda_{\mathrm{UV}}=330 \mathrm{~nm}$, while the absorbance at other wavelength is almost invariant.

Generally, the following excited states are important for organometallic complex $\left.{ }^{17}: 1\right)$ L-F or $\mathrm{d}-\mathrm{d}$ excitation: Change in electron displacement between d-orbitals of metal ion. 2) IL excitation: Change in electron displacement within ligand molecules. 3) Charge transfer (CT) excitation: Donation or acceptance of electron between metal and ligand. Besides the above, other effects such as an electron transfer from metal complex to solvent and an excitation of electron on metal-metal bondage might occur but may be minor ones.

It is a well-known fact that copper forms copper-ammnine complex in ammonia solution and the band at $630 \mathrm{~nm}$ has been identified as the $d-d$ transition of cupric ion. ${ }^{18}$ Since the peaks observed at less than $400 \mathrm{~nm}$ for the

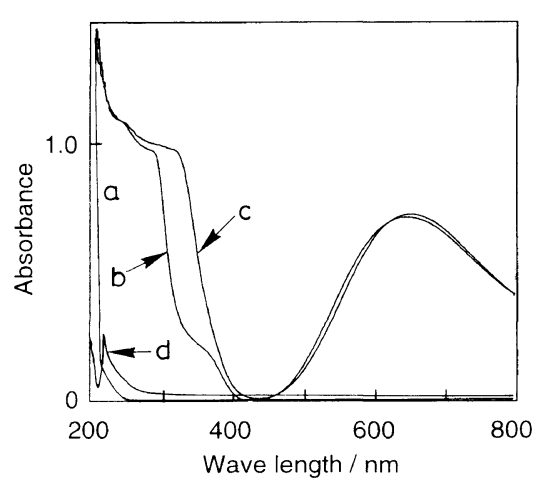

Figure 1. Absorption spectra of aq $15 \mathrm{wt} \% \mathrm{NH}_{3}$ solution (a), aq cuprammonium solution (b), cellulose-aq cuprammonium solution (c), and cellulose-aq sodium hydroxide solution (d). 
cuprammonium solution were not detected for aq $\mathrm{NH}_{3}$ solution and the appearance of absorption in near UV region due to $\mathrm{d}-\mathrm{d}$ transition of cupric ion has never been reported, then these three peaks $(330,300,260 \mathrm{~nm})$ may be responsible for $\mathrm{CT}$ absorption derived from a formation of complex between $\mathrm{Cu}$ and $\mathrm{NH}_{3}$, $\mathrm{OH}, \mathrm{H}_{2} \mathrm{O}$. It is well-known as an empirical fact for aq cobalt complex $\mathrm{Co}\left(\mathrm{NH}_{3}\right)_{6}^{3+}$ that the CT absorptions between cobalt ion and $\mathrm{NH}_{3}, \mathrm{OH}$, $\mathrm{H}_{2} \mathrm{O}$ are observed in $\mathrm{UV}$ region and the peak wave length shifts to longer wavelength side by the ligand species in the order of $\mathrm{NH}_{3}, \mathrm{H}_{2} \mathrm{O}$, $\mathrm{OH}^{-19}$. If we dare to apply the above fact to the present aq cuprammonium solution, the absorption at 260,300 , and $330 \mathrm{~nm}$ might be attributed to the complexes mainly formed between $\mathrm{Cu}-\mathrm{NH}_{3}, \mathrm{Cu}-\mathrm{H}_{2} \mathrm{O}, \mathrm{Cu}-\mathrm{OH}$, respectively. This indirectly predicts that peak wavelength for absorption depends strongly on the stability or strength of the complex caused by circumstances.

Regarding absorption spectrum of the cellulose-cuprammonium solution (c), the absorption peak near $\lambda_{\mathrm{UV}}=630 \mathrm{~nm}$ due to $\mathrm{d}-\mathrm{d}$ transition of cupric ion seems to slightly shift to higher wave length but almost constant in its intensity by dissolution of cellulose, indicating that transition energy level of $d-d$ transition of cupric ion is not so influenced by dissolution of cellulose. In contrast to this, the band around at $330 \mathrm{~nm}$ observed for aq cuprammonium solution strongly increases in its intensity by addition of cellulose. The increase of the intensity $(\Delta I)$ for the band $(c a .330 \mathrm{~nm})$ is accelerated by increase of cellulose amount in the systems, as demonstrated in Figure 2, where the subtracted spectra obtained by subtracting the spectra of aq cuprammonium hydroxide solution from those of cellulose solution are shown. Inspection of Figure 1(d) reveals that the cellulose in aq $\mathrm{NaOH}$ solution does not show any absorption around at $\lambda_{\mathrm{UV}}=$ $330 \mathrm{~nm}$. In the figure the small absorbance at $\lambda=230 \mathrm{~nm}$ is considered due to contamination of lignin and hemicellulose. These facts indicate

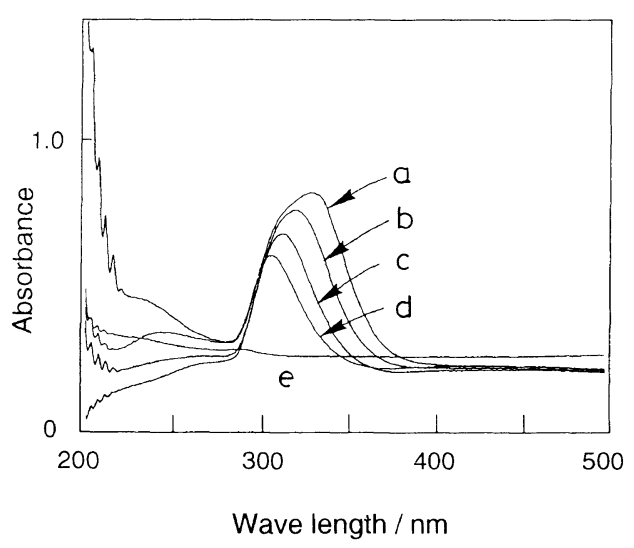

Figure 2. Subtracted spectra of cellulose-aq cuprammonium solution with cellulose concentration of $1.6 \mathrm{wt} \%$ (a), $0.8 \mathrm{wt} \%$ (b), $0.4 \mathrm{wt} \%$ (c), $0.2 \mathrm{wt} \%$ (d), and $0 \mathrm{wt} \%$ (e).

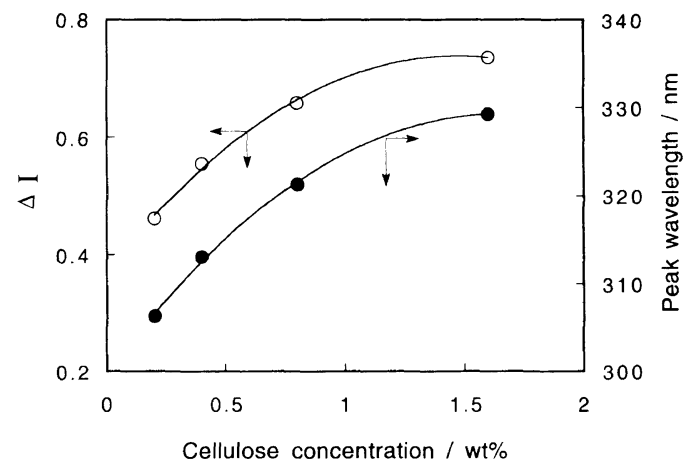

Figure 3. Plots of the peak intensity and peak wavelength of absorption spectra in Figure 2 against cellulose concentration.

that this band is attributable to CT excitation between cupric ion and oxygen atom of hydroxyl group of cellulose. The above conclusion might be supported by the report ${ }^{20}$ that CT excitation of complex of cupric ion and amino acids takes place in UV range.

Cellulose concentration $\left(C_{\mathrm{p}}\right)$ dependence of the peak wavelength and the intensity $(\Delta I)$ of CT absorption is indicated in Figure 3. With an increase in cellulose amount in the system, the peak wavelength shifts to higher wavelength and the intensity monotonically increases. In Figure 4, the effect of the concentration of copper and cellulose on the UV spectra is shown for the cellulose-cupram- 


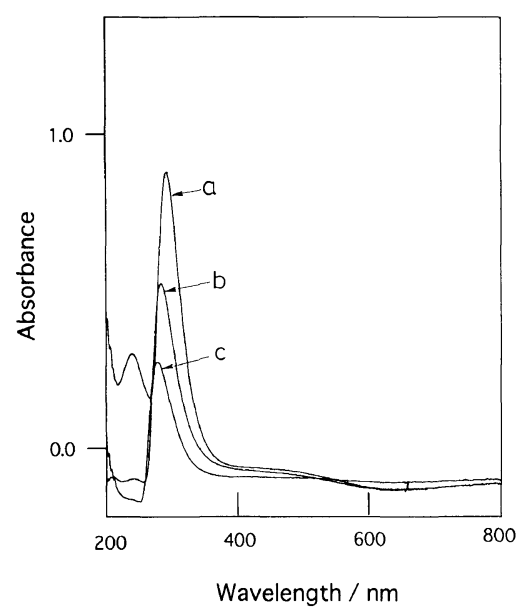

Figure 4. Absorption spectra of cellulose-aq cuprammonium-cellulose solution $\mathrm{Cu} / \mathrm{NH}_{3} / \mathrm{H}_{2} \mathrm{O}(\mathrm{wt} \%)=0.5 / 12.5 /$ 0.32 (a), $\mathrm{Cu} / \mathrm{NH}_{3} / \mathrm{H}_{2} \mathrm{O}(\mathrm{wt} \%)=0.25 / 12.5 / 0.16$ (b), and $\mathrm{Cu} / \mathrm{NH}_{3} / \mathrm{H}_{2} \mathrm{O}\left(\mathrm{wt}^{\circ} / \mathrm{H}\right)=0.16 / 12.5 / 0.10$ (a).

monium solution in which the weight ratio of copper and cellulose is maintained constant. Each subtracted spectrum of the cellulose solution in the figure is obtained by subtracting the spectrum of aq cuprammonium solution from that of the cellulose solution with the same $\mathrm{Cu}$, $\mathrm{NH}_{3}, \mathrm{H}_{2} \mathrm{O}$ composition. When the concentration of copper, accordingly cellulose, decreases, the peak wavelength of CT transition shifts to lower wavelength and the differential absorbance at $\lambda_{\mathrm{UV}}=330 \mathrm{~nm}$ remarkably decreases. This indicates that copper amount in the solution is another factor to determine the peak wavelength and its intensity, as far as the CT transition is concerned.

Intensity for the $\mathrm{CT}$ excitation might be a function of cellulose-cuprammonium complex concentration in the system if cellulose, cuprammonium complex, and cellulose-cuprammonium complex in the system are in equilibrium. It is important to reveal the molar ratio of copper/glucopyranose unit (hereafter, simply referred to $\mathrm{Cu} / \mathrm{Cell}$ ratio) for the cellulose-cuprammonium complex in the system. Unfortunately, cellulose could not be completely dissolved in aq cuprammonium hydroxide unless $\mathrm{Cu} / \mathrm{Cell}$ ratio surpass 0.5 and

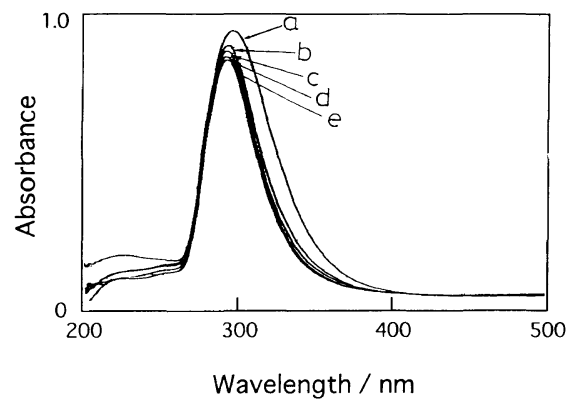

Figure 5. Subtracted spectra of cellulose-aq cuprammonium and cellulose oligomer-aq cuprammonium solution. $\mathrm{Cu}$ concentration $=0.5 \mathrm{wt} \% ; \mathrm{NH}_{3}$ concentration $=$ $12.5 \mathrm{wt} \%$; cellulose oligomer and cellulose concentration = $0.25 \mathrm{wt} \%$. a) glucose; b) cellobiose; c) cellotriose; d) cellotetraose; e) cellulose.

then cellulose oligomers were used for this purpose. Figure 5 shows subtracted UV spectra of glucose, cellobiose, cellotriose, cellotetraose, and cellulose dissolved with the solute concentration of $0.25 \mathrm{wt} \%$ in aq cuprammonium hydroxide. The spectrum of every solution exhibits the absorbance peak around $\lambda_{\mathrm{UV}}=290$ $\mathrm{nm}$ due to CT transition. The peak position is almost independent of the solute, but the peak height tends to decrease with increasing number of glucose units for the solute molecules. As discussed later (see Figures 12 and 13), cupric ions possibly coordinate with hydroxyl groups of the oligomer and cellulose molecules in the solution, forming chelate and the number of chelates per glucose unit should decrease with an increase in the length of the solute molecule. This is considered to cause the lowering of the peak height. Since the peak position is independent of the samples, the effect of $\mathrm{Cu} /$ Cell ratio on the absorption intensity of $\mathrm{CT}$ transition was investigated using cellotetraose and cellopentaose as models of cellulose.

Figure 6 shows the plot of intensity difference $(\Delta I)$ of the $\mathrm{CT}$ absorption against $\mathrm{Cu}$ / Cell ratio initially charged for the systems of cellotetraose (a) and cellopentaose (b). $\Delta I$ for both systems rapidly increases with an increase in $\mathrm{Cu} / \mathrm{Cell}$ ratio in the $\mathrm{Cu} / \mathrm{Cell}$ range less than 0.6 and tends to level off at $\mathrm{Cu} / \mathrm{Cell}$ ratio more 


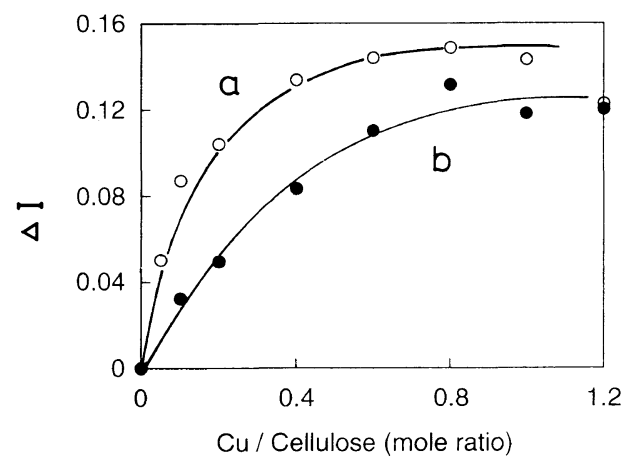

Figure 6. The Intensity $(\triangle)$ and peak wavelength of CT absorption bands of cellulose oligomer-cuprammonium systems plotted against the initial $\mathrm{Cu} / \mathrm{Cell}$ ratio. a) cellotetraose; b) cellopentaose.

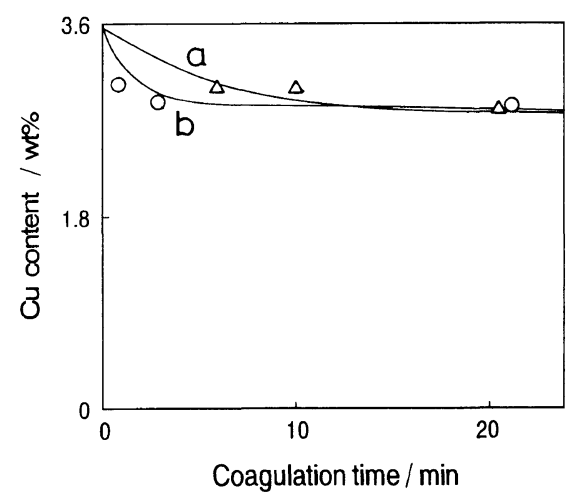

Figure 7. Coagulations time dependence of the liberation of copper from cellulose-aq cuprammonium solution by water at $9^{\circ} \mathrm{C}$ (a) and $40^{\circ} \mathrm{C}(\mathrm{b})$. Concentration of initial solution: $\mathrm{Cu}=3.6 \mathrm{wt} \% ; \mathrm{NH}_{3}=7.0 \mathrm{wt} \% ;$ cellulose $=10$ $\mathrm{wt} \%$.

than 0.6. If this result is applicable to cellulose in aq cuprammonium hydroxide, in the $\mathrm{Cu}$ / Cell range more than $0.6-0.8$ the liberated cuprammonium complex coexists with cellulose-cuprammonium complex in the system. This does not contradict the past observation that cellulose does not dissolve in aq cuprammonium hydroxide at the cellulose concentration up to $10 \mathrm{wt} \%$ when $\mathrm{Cu} / \mathrm{Cell}$ ratio initially charged for the system is less than unity. ${ }^{21}$

Figure 7 demonstrates that liberation of copper from cellulose-aq cuprammonium hydroxide solution with $\mathrm{Cu} / \mathrm{Cell}$ ratio of unity by water at $9^{\circ} \mathrm{C}(\mathrm{a})$ and $40^{\circ} \mathrm{C}(\mathrm{b})$. The liberation

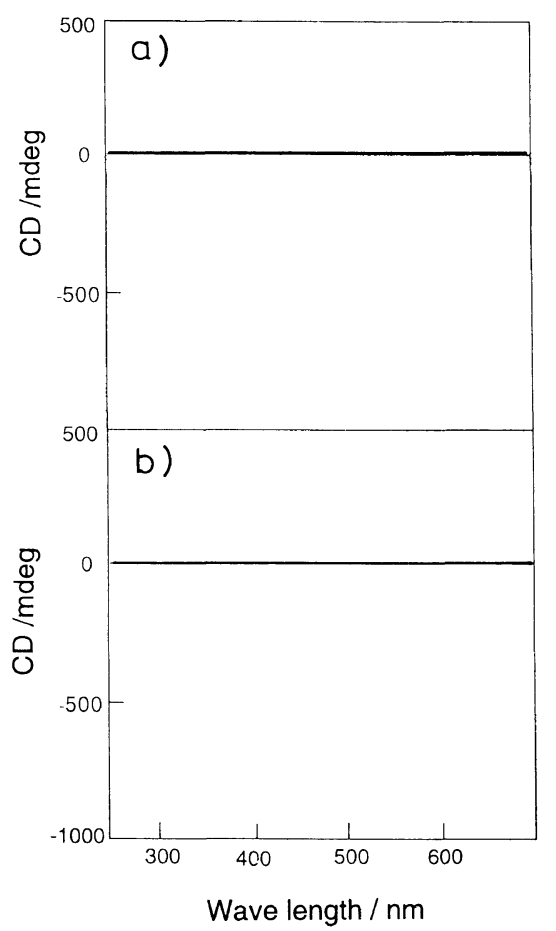

Figure 8. CD spectra of aq cuprammonium solution with $\mathrm{Cu} / \mathrm{NH}_{3} / \mathrm{Cell}=0.8 / 12.5 / 1.0 \mathrm{wt} \%$ (a) and cellulose-aq sodium hydroxide solution (b).

of copper at both temperatures saturates to $20-25 \%$, which coincides with the $\mathrm{Cu} / \mathrm{Cell}$ ratio giving level-off $\Delta I$. These phenomenogical facts should be considered in relation to conformation of cellulose-cuprammonium complex and ligand position.

Figure 8 shows CD spectra of aq cuprammonium hydroxide (a) and cellulose-aq $\mathrm{NaOH}$ (b) and Figure 9 shows CD spectra of cellulose-aq cuprammonium hydroxide systems. Obviously, no CD peak is observed for the former system. For the latter system, a negative CD peak around $300 \mathrm{~nm}$ and a broad positive CD peak around $600 \mathrm{~nm}$ are observed. The CD peak around $300 \mathrm{~nm}$ increases in its intensity and shifts towards higher wave length as cellulose content increases, which just corresponds to the peak shift and change in its intensity of UV absorption near $\lambda_{\mathrm{UV}}=300 \mathrm{~nm}$, indicated in Figure 3. Of course, the latter peak 
intensity increases with an increase of cellulose concentration. As a rule, Cotton effect can be detected 1) when the absorption exists in the observed wave length range and 2) when asymmetric molecules exist in the system. Aq cuprammonium hydroxide system satisfies condition 1) (see Figure 1) but not satisfy condition 2). For cellulose-aq $\mathrm{NaOH}$, condition 1) is not satisfied so that no CD peak is detectable. The cellulose-aq cuprammonium hydroxide system accords with the both conditions because there are observed $\mathrm{d}-\mathrm{d}$ excitation ( $c a .600 \mathrm{~nm})$ and CT excitation ( $c a$. $300 \mathrm{~nm}$ ) absorptions and the formation of cellulose-cuprammonium complex which probably has asymmetric nature. Origin of the

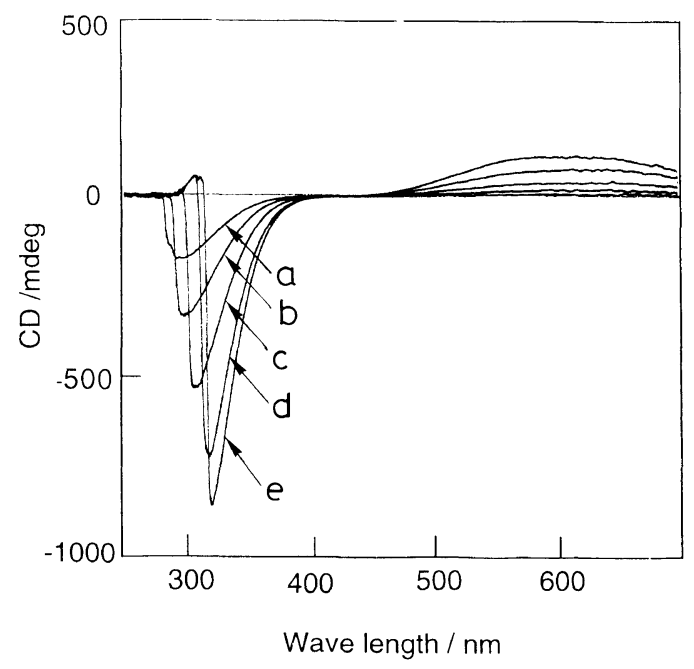

Figure 9. $\mathrm{CD}$ spectra of cellulose-aq cuprammonium solution with $\mathrm{Cu}$ and $\mathrm{NH}_{3}$ concentrations of 0.8 and $12.5 \mathrm{wt} \%$, respectively. a) $0.1 \mathrm{wt} \%$; b) $0.2 \mathrm{wt} \%$; c) $0.4 \mathrm{wt} \%$; d) $0.8 \mathrm{wt} \%$; e) $1.6 \mathrm{wt} \%$.
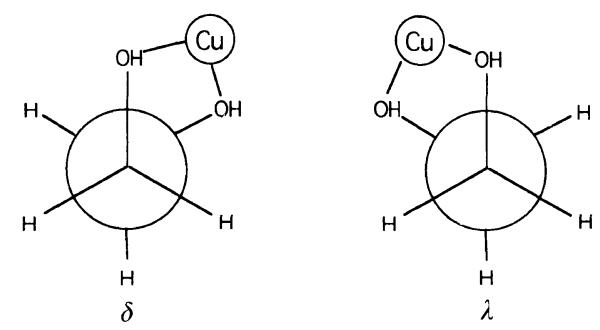

Figure 10. Newman's projections of $\delta$ and $\lambda$ structures of copper chelate. asymmetric cite of organometallic complex is mainly related to the following three effects: 1 ) Configuration of chelate ligand, 2) conformation of chelate ligand, 3) optical activity ligand itself. As described before, Bukhari et al. reported that symbols of $C D$ peak for chelate compound of cyclic 1,2 diols containing copper are reversed depending on whether the chelate comformation takes a form of $\delta$ or $\lambda$ structure (see Figure 10 and corresponding CD patterns are shown in Figure 1 in ref 11). Judging from CD spectrum pattern of cellulose-aq cuprammonium solution, cellulose-cuprammonium complex might take a form of $\delta$ structure. A monomer unit of cellulose, that is $\beta$-Dglucose takes 6-membered chair conformation and all hydroxyl groups at $\mathrm{C}_{2}, \mathrm{C}_{3}$, and $\mathrm{C}_{6}$ are arranged equatorially. In this case, the angle between hydroxyl groups at $\mathrm{C}_{2}$ and $\mathrm{C}_{3}$ is $60^{\circ}$ and is only possible to give $\delta$ structure with copper, as shown in Figure 11.

Figure 12 shows CD spectra of cellulose oligomers in cuprammonium hydroxide. Obviously, positive CD peak around $300 \mathrm{~nm}$ is observed for glucose and cellobiose although peak intensity is higher for the former than that for the latter. In contrast to this, negative CD peak appears for cellotriose, cellopentaose, and cellulose and its intensity increases with an increase in number of glucose units. For glucose, chelating of copper is possible at $\mathrm{C}_{1}-\mathrm{C}_{2}, \mathrm{C}_{2}-\mathrm{C}_{3}$, and $\mathrm{C}_{3}-\mathrm{C}_{4}$ positions and except for $\mathrm{C}_{2}-\mathrm{C}_{3}$ position $\lambda$ structure is stable, as shown in Figure 13. Therefore, $\lambda$ structure is numerically superior $\delta$ structure, generating relatively large positive $\mathrm{CD}$ peak. Since for cellobiose one reducing end $\mathrm{C}_{1}$ and one non-

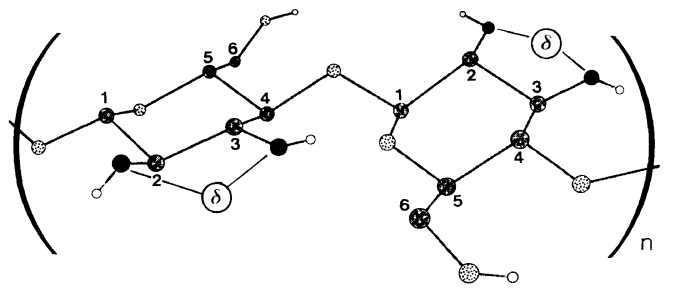

Figure 11. Schematic representation of conformation of the cellulose-cuprammonium complex. 


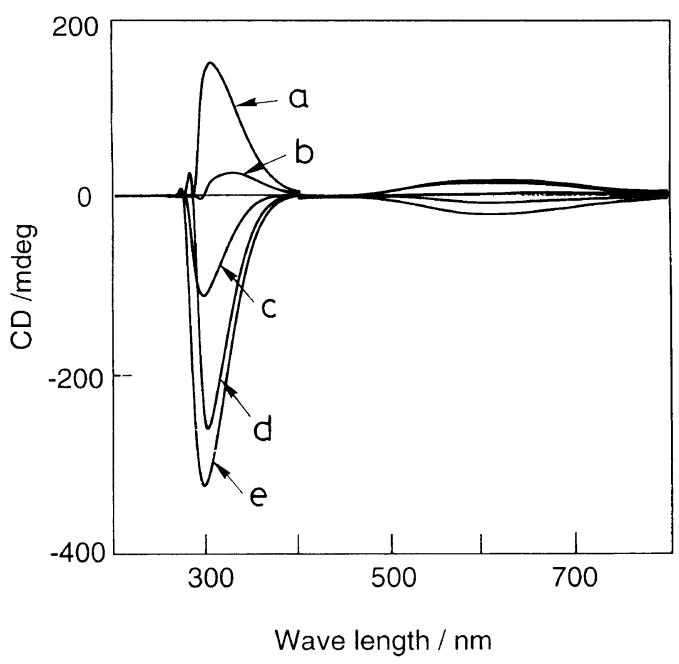

Figure 12. CD spectra of cellulose oligomer-aq cuprammonium solution. a) glucose, b) cellobiose, c) cellotriose, d) cellopentaose, and e) cellulose. $\mathrm{Cu}$ concentration $=0.8$ $\mathrm{wt} \% ; \mathrm{NH}_{3}$ concentration $=12.5 \mathrm{wt} \%$; oligomer concentration $=1.0 \mathrm{wt} \%$.

a)

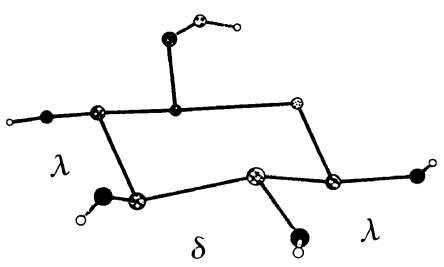

b)

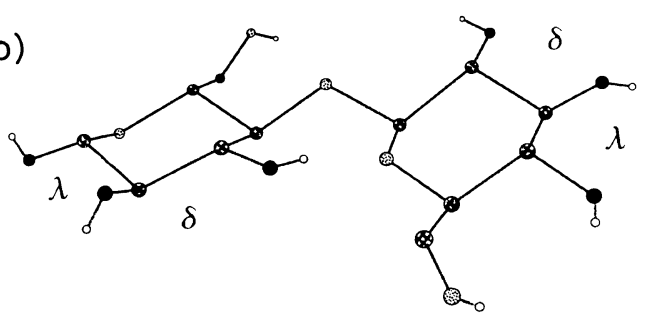

Figure 13. Considerable chelate conformation of copper and cellulose oligomer. a) glucose; b) cellobiose.

reducing end $\mathrm{C}_{4}$ are linked by $\beta$-glycosidic linkage, the probability of $\delta$ and $\lambda$ structures are equal, leading to a depressed positive CD peak. Likewise, for cellulose oligomers with more than 3 glucose units, the probability of $\delta$ structure increases with an increase in molecular chain length, giving larger negative $C D$

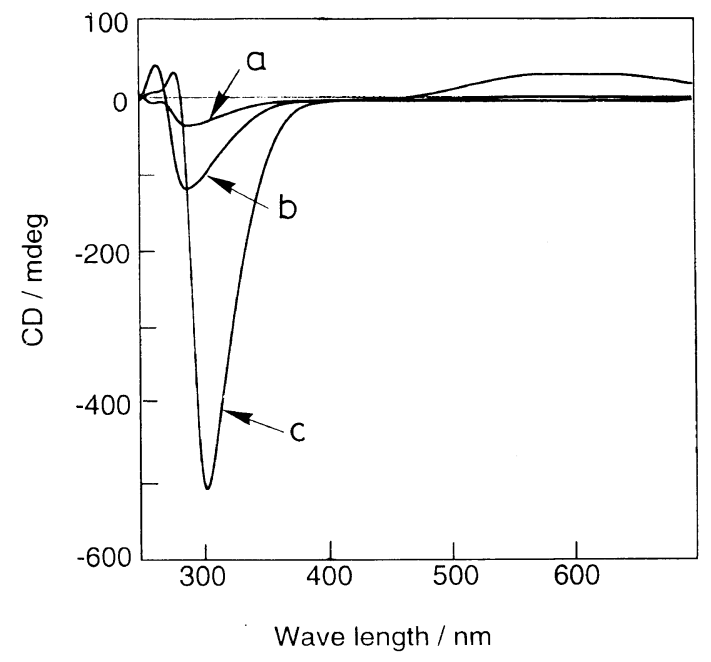

Figure 14. CD spectra of cellulose-aq cuprammonium solution and $\mathrm{MC}$-aq cuprammonium solution a) $\mathrm{SMC}$, b) $\mathrm{RMC}$, and c) cellulose. $\mathrm{Cu}$ concentration $=0.8 \mathrm{wt} \%$; $\mathrm{NH}_{3}$ concentration $=12.5 \mathrm{wt} \%$; polymer concentration $=$ $1.0 \mathrm{wt} \%$.

peaks. This consideration gives plausible explanation for the above experimental facts although discussion is needed on the energetical stability of $\delta$ and $\lambda$ structures in the solution. As mentioned before, Reeves et al. reported on the methyl glucose (MG)-cuprammonium solution system that the $\mathrm{MG}$ substituted by methyl group at $\mathrm{C}_{2}$ and $\mathrm{C}_{3}$ positions indicates lower levorotation, comparing to the case of MG which is free from methyl group at the both positions, and $\mathrm{MG}$ with no methyl groups at $\mathrm{C}_{4}, \mathrm{C}_{2}$, and $\mathrm{C}_{3}$ shows far lower levorotation. These very interesting results support our speculation, because equal occurring probability of $\delta$ and $\lambda$ structures which may be realized for $\mathrm{MG}$ with unsbstituted hydroxyl groups at $\mathrm{C}_{2}, \mathrm{C}_{3}$, and $\mathrm{C}_{4}$ positions, leads to very low circular dichroism.

Figure 14 demonstrates that $\mathrm{C}_{2}-\mathrm{C}_{3}$ positions are suitable site for coordination of cuprammonium complex. Here, CD spectra of RMC, SMC, and cellulose in aq cuprammonium hydroxide are shown. Intensity of CD peak attributed to charge transfer is in the order of Cellulose $\gg$ RMC $>$ SMC. This means that 
methylation of hydroxyl group leads to the lowering in CT intensity. Since $\langle\langle F\rangle$ is larger for RMC than SMC and if all hydroxyl groups participate in the complex formation, the itensity of CT excitation should be larger for SMC than RMC.

\section{CONCLUSION}

An attempt was made to clarify the dissolved state of cellulose in aq cuprammonium hydroxide solution using UV and CD spectrophotometry on cellulose and its oligomers in the solution. Negative Cotton effect and positive Cotton effect for the cellulose-cuprammonium solution are observed at $300-350 \mathrm{~nm}$ and $c a .600 \mathrm{~nm}$. The former Cotton effect seems to originate from CT excitation and the latter from $d-d$ excitation of cupric ion due to coordination of cuprammonium complex to hydroxyl group of cellulose. The former CD strength becomes larger depending on cellulose concentration and at the same time its position shifted toward longer wave number.

Consideration on conformation of glucopyranose unit and the experimental fact that intensity of $\mathrm{CD}$ for almost $\mathrm{C}_{2}-\mathrm{C}_{3}$ substituted methyl cellulose in cuprammonium hydroxide is nearly zero leads us to an conclusion that cuprammonium complex coordinates preferentially to hydroxyl groups at $\mathrm{C}_{2}$ and $\mathrm{C}_{3}$, giving $\delta$ chelate form. As a dissolved state of cellulose in aq cuprammonium hydroxide, an equilibrium state between cellulose-cuprammonium complex, cellulose and cuprammonium hydroxide was predicted where copper/cellulose molar ratio of $c a .0 .6-0.8$ is stable for the cellulose-cuprammonium complex.

\section{REFERENCES}

1. E. Schweizer, J. Pract. Chem., 72, 109 (1857).

2. H. Pauly, DR Patent 98642, Br. Patent 28631 (1897).

3. W. Gibson, L. Soencer, and R. McCall, J. Chem. Soc., 117, 479 (1920).

4. M. Tsuge, S. Uematsu, Y. Ono, S. Eiga, and M. Makita, Japan Open Patent 49-13424.

5. W. Traube, Ber., 54, 3220 (1921).

6. T. Lieser and R. Ebert, Ann., 528, 281,532, 89 (1925).

7. S. M. Neal, J. Text. Inst., 16, T363 (1925).

8. K. Hess and E. Messmer, Ber., 55, 2441 (1922).

9. R. E. Reeves, Science, 99, 148 (1944).

10. S. T. K. Bukhari, R. D. Guthrie, A. I. Scott, and A. D. Wrixon, Chem. Commun., 1580 (1968).

11. S. T. K. Bukhari, R. D. Guthrie, A. I. Scott, and A. D. Wrixon, Tetrahedron, 26, 3653 (1970).

12. T. Yamashiki, T. Matsui, M. Saitoh, K. Okajima, K. Kamide, and T. Sawada, Br. Polym. J., 22, 73 (1990).

13. W. Brown and R. Wikström, Eur. Polym. J., 1, 1, (1965).

14. K. Kamide, K. Okajima, T. Matsui, and K. Kowsaka, Polym. J., 16, 857 (1984).

15. T. Kondo and D. G. Gray, Carbohydrate Res., 220, 173 (1991).

16. S. Takahashi, T. Fujimoto, B. M. Barua, T. Miyamoto, and H. Inagaki, J. Polym. Sci. Polym. Chem. Ed., 24, 2981 (1986).

17. A. Sugimori, in "Yuki Koukagaku," H. Iguchi, M. Oki, and G. Tanaka, Ed., Shokabo, Tokyo, 1991, p 243, Chapter 15.

18. The Chemical Society of Japan, Ed., "Kagaku Binran-Kisohen," Vol. II, Maruzen Co., Tokyo, 1987, Chapter 14, p 338.

19. K. Saito, in "Atarashii Sakutaino Kagaku," Nippon Kagakukai, Ed., Dainippontosho Publishing Co., Tokyo, 1986, p 76, Chapter 3.

20. C. Ibarra, R. Soto, L. Adan, A. Decinti, and S. Bunel, Inorg. Chem. Acta, 6, 601 (1972).

21. K. Nojima and A. Terabaru, unpublished data. 